\title{
Article
}

\section{Electrocatalysis of dopamine in the presence of uric acid and folic acid on modified carbon nanotube paste electrode}

\author{
Mohammad Mazloum-Ardakani a,*, Mahboobe Abolhasani ${ }^{a}$, Bibi-Fatemeh Mirjalilia , \\ Mohammad Ali Sheikh-Mohseni ${ }^{b}$, Afsaneh Dehghani-Firouzabadi a, Alireza Khoshroo ${ }^{a}$ \\ a Department of Chemistry, Faculty of Science, Yazd University, Yazd, Iran \\ b Shahid Bakeri High Education Center of Miandoab, Urmia University, Urmia, Iran
}

\section{A R T I C L E I N F}

\section{Article history:}

Received 25 August 2013

Accepted 22 October 2013

Published 20 February 2014

\section{Keywords:}

Electrocatalysis

Dopamine

Uric acid

Folic acid

Carbon nanotube

Voltammetry

\begin{abstract}
A B S T R A C T
A chemically modified carbon paste electrode (CPE), consisting of 2,2'-[(1E)-(1,2-phenylenebis (azanylylidene)]bis(methanylylidene)]bis(benzene-1,4-diol) (PBD) and multiwalled carbon nanotubes (CNTs), was used to study the electrocatalytic oxidation of dopamine using cyclic voltammetry, chronoamperometry, and differential pulse voltammetry (DPV). First, the electrochemical behavior of the modified electrode was investigated in buffer solution. Then the diffusion coefficient, electrocatalytic rate constant, and electron-transfer coefficient for dopamine oxidation at the surface of the PBD-modified CNT paste electrode were determined using electrochemical approaches. It was found that under optimum conditions $(\mathrm{pH}=7.0)$, the oxidation of dopamine at the surface of such an electrode occurred at about $200 \mathrm{mV}$, lower than that of an unmodified CPE. DPV of dopamine at the modified electrode exhibited two linear dynamic ranges, with a detection limit of 1.0 $\mu \mathrm{mol} / \mathrm{L}$. Finally, DPV was used successfully for the simultaneous determination of dopamine, uric acid, and folic acid at the modified electrode, and detection limits of 1.0, 1.2, and $2.7 \mu \mathrm{mol} / \mathrm{L}$ were obtained for dopamine, uric acid, and folic acid, respectively. This method was also used for the determination of dopamine in a pharmaceutical preparation using the standard addition method.
\end{abstract}

(C) 2014, Dalian Institute of Chemical Physics, Chinese Academy of Sciences. Published by Elsevier B.V. All rights reserved.

\section{Introduction}

Dopamine (DA) is an important neurotransmitter. It belongs to the catecholamine group and plays a significant role in the central nervous, renal, hormonal, and cardiovascular systems $[1,2]$. Dysfunction of the dopaminergic system in the central nervous system has been related to neurological disorders such as schizophrenia and Parkinson's disease [3]. Various commonly usable analytical methods for DA and its analogs have therefore been developed in the past. Some examples of these methods are rapid liquid chromatography/tandem mass spectrometry [4], chromatography methods [5-7], and capillary electrophoresis mass spectrometry [8]. These methods are very sensitive but require compressing systems, temperature-controlling systems, separation systems, and other spectrophotometric or electric detection systems. Electrochemical detection of DA has attracted much interest because of the importance of DA in the central nervous system. A significant problem in DA determination is fouling effects caused by accumulation of reaction products, which form electropolymerized films on the electrode surface [9]. One promising approach to overcoming problems arising from fouling of the biological substrate is the use of electrocatalysis at chemically modified electrodes (CMEs) [10-12].

Uric acid (UA) is a primary end product of purine metabolism. Abnormal levels of UA are symptoms of several diseases 
such as gout, hyperpiesia, and Lesch-Nyhan syndrome [13]. Monitoring of the concentration of UA in biological fluids can therefore be used as an early warning of the presence of these diseases. Colorimetric, enzymatic, and electrochemical methods are used to determine the concentration of UA [14,15]. Colorimetric methods are unreliable for accurate determination of UA concentration. Although determination of UA by enzymatic methods is promising because of their high selectivities, this methodology is inherently expensive and does not have a good detection limit. Electrochemical methods for the determination of UA are more selective, less expensive, and less time-consuming than other methods [16].

Folic acid (FA) is a water-soluble vitamin B, which helps to build healthy cells. A deficiency of FA is a common cause of anemia and is thought to increase the likelihood of heart attack and stroke. Many studies suggest that diminished folate status is associated with enhanced carcinogenesis because FA, along with vitamin B12, participates in nucleotide synthesis, cell division, and gene expression [17]. Periconceptual supplementation of FA has been demonstrated to significantly reduce the incidence and recurrence of neural tube defects such as spina bifida in women [18]. A survey of the literature reveals that there are various methods available for the determination of FA, including liquid chromatography [19,20], flow-injection chemiluminometry [21], isotope dilution-liquid chromatography/tandem mass spectrometry [22], and spectrophotometric methods [23]. FA is an electroactive component, so some electrochemical methods have been reported for its determination [24]. Electrochemical methods are more desirable than other techniques because they are convenient and low cost.

Carbon-based electrodes are among the most commonly used electrodes in voltammetric analysis because of their low cost, wide potential windows, low electrical resistances, and versatility of chemical modification [25]. The use of carbon paste as an electrode has been applied in the preparation of CMEs for several purposes, such as electrochemical sensors for the analysis of biologically important compounds [26,27] and for electrocatalysis [28-30]. The chemical modification of electrodes using electron-transfer mediators is an interesting area of analytical chemistry [31]. One of the most important effects of any mediator is the reduction in the overpotential required for electrochemical reactions, which enhances the sensitivity and selectivity of the method [32,33]. In one type of modified electrode, known as electrocatalytic modified electrodes, a redox-active modifier uses as an electrocatalyst to catalyze oxidation of a substance.

Nanostructures with large specific surface areas provide important and feasible platforms for catalysis [34], separation [35], sorption [36], sensing [37], and fuel cells [38]. Carbon nanotubes (CNTs) are one of the most actively studied materials because of their finite small size, high specific surface area, high porosity, and unique physical, chemical, and electrical properties $[39,40]$. In electrocatalysis, the use of nanomaterials and CNTs significantly enhances the electron-transfer kinetics and mass transport [41-43].

In this study, we synthesized 2,2'-[(1E)-(1,2-phenylenebis (azanylylidene))bis(methanylylidene)]bis(benzene-1,4-diol)
(PBD) and studied its electrochemical behavior in a PBD-modified CNT paste electrode (PBDCNPE). The experimental results showed that PBD has appropriate redox behavior for use as a good modifier in the construction of redox-active-modified electrode. We therefore investigated the suitability of this modified electrode as a new electrocatalyst for the electrocatalysis of DA; satisfactory results were obtained. In addition, we evaluated the analytical performance of the modified electrode for DA quantification in the presence of UA and FA. Finally, to demonstrate the catalytic potential of this modified electrode for electro-oxidation of DA in real samples, we examined this method for the voltammetric determination of DA in ampoule preparations.

\section{Experimental}

\subsection{Apparatus and reagents}

The electrochemical measurements were performed using a potentiostat/galvanostat (SAMA 500 electroanalyzer system, Iran). A three-electrode cell was used at $25 \pm 1^{\circ} \mathrm{C}$. A saturated calomel electrode (SCE), a platinum wire, and the PBDCNPE were used as the reference, auxiliary, and working electrodes, respectively. All potentials in this work are reported versus SCE. The pH measurements were carried out using a Metrohm model $691 \mathrm{pH} / \mathrm{mV}$ meter. All solutions were prepared using doubly distilled water. DA, UA, FA, and other reagents were analytical grade (Merck). Phosphate buffer solutions (0.1 mol/L) were prepared from $\mathrm{H}_{3} \mathrm{PO}_{4}-\mathrm{NaH}_{2} \mathrm{PO}_{4}(0.1 \mathrm{~mol} / \mathrm{L})$, and the $\mathrm{pH}$ was adjusted with $\mathrm{H}_{3} \mathrm{PO}_{4}$ or $\mathrm{NaOH}(0.1 \mathrm{~mol} / \mathrm{L})$. Graphite paste was prepared from two main components, i.e., graphite powder (Merck) and paraffin oil (DC 350, Merck, density $=0.88$ $\left.\mathrm{g} / \mathrm{cm}^{3}\right)$.

\subsection{Synthesis of 2,2'-[1,2-phenylenediyl- bis(nitrilomethylidene)]bis(4-hydroxyphenol)}

1,2-Phenylenediamine $(0.15 \mathrm{~g}, 1.4 \mathrm{mmol})$ was added to a mixture of 2,5-dihydroxybenzaldehyde $(0.35 \mathrm{~g}, 2.5 \mathrm{mmol})$ in methanol; the mixture was stirred for $30 \mathrm{~min}$. The progress of the reaction was monitored using thin-layer chromatography. After the reaction was complete, the red solid product was removed by filtration and washed with cold methanol. The pure desired Schiff base was obtained in $96 \%$ yield. The Schiff base product was identified from its physical and spectroscopic data. Red solid. Yield: $96 \%$. Mp: $270-272{ }^{\circ} \mathrm{C}$. Anal. Calcd: C 68.9, H 4.6, N 8.04; Found: $\mathrm{C}$ 68.7, $\mathrm{H}$ 4.9, N 7.7. IR $\left(\mathrm{KBr}, \mathrm{cm}^{-1}\right): v$ 3250-3500 (s, br, 20H), 1619 (s, C=N), 1572, 1488 (Ar), 1289 (s, C-0). ${ }^{1} \mathrm{H}$ NMR (400 MHz/DMSO- $d_{6}$ ): $\delta 12.13$ (br, 2OH, intramolecular hydrogen bonding), $9.10(\mathrm{br}, 2 \mathrm{OH}), 8.79$ (s, 2CH imine), 7.40 (dd, 2H, Ar, $J_{1}=8.2 \mathrm{~Hz}, J_{2}=2.3 \mathrm{~Hz}$ ), 7.37 (dd, $2 \mathrm{H}, \mathrm{Ar}$, $J_{1}=8.3 \mathrm{~Hz}, J_{2}=2.3 \mathrm{~Hz}$ ), $7.02(\mathrm{~d}, 2 \mathrm{H}, \mathrm{Ar}, J=2.8 \mathrm{~Hz}), 6.86(\mathrm{dd}, 2 \mathrm{H}$, $\left.\mathrm{Ar}, J_{1}=8.1 \mathrm{~Hz}, J_{2}=2.7 \mathrm{~Hz}\right), 6.78(\mathrm{~d}, 2 \mathrm{H}, \mathrm{Ar}, J=8.8 \mathrm{~Hz}) .{ }^{13} \mathrm{C} \mathrm{NMR}$ (100 MHz/DMSO-d6): $\delta 164.28,153.73,150.04,142.98,128.03$, 121.77, 120.28, 119.88, 117.38, 117.27. MS: $m / z=348\left(\mathrm{M}^{+}, 3\right)$, 212 (10), 129 (14), 92 (78), 93 (14), 80 (42), 77 (47), 65 (100). $\mathrm{UV} / \lambda_{\max }(\mathrm{nm}): 360(\mathrm{~s}), 260(\mathrm{w})$. 


\subsection{Preparation of electrodes as electrocatalysts}

The PBDCNPEs were prepared by mixing $0.94 \mathrm{~g}$ of graphite powder, $0.03 \mathrm{~g}$ of PBD, $0.03 \mathrm{~g}$ of CNT, and $0.7 \mathrm{~mL}$ of paraffin oil with a mortar and pestle until a uniformly wetted paste was obtained. These amounts of materials were obtained by optimization. The paste was then packed into the end of a glass tube (ca. $3.5 \mathrm{~mm}$ i.d. and length $10 \mathrm{~cm}$ ). A copper wire inserted into the carbon paste provided an electrical contact. When necessary, the surface of the carbon paste was polished with a smooth paper to obtain a shiny appearance. For comparison, a PBD-modified carbon paste electrode (CPE) without CNTs (PBDCPE), a CNT paste electrode without PBD (CNPE), and an unmodified CPE, i.e., without PBD and CNT, were also prepared in the same way.

\section{Results and discussion}

\subsection{Electrochemical behavior of PBDCNPE}

PBD is insoluble in aqueous media; we prepared the PBDCNPE and studied its electrochemical properties in a buffered aqueous solution using cyclic voltammetry (CV). The CVs for the modified electrode at different scan rates in phosphate buffer (pH 7.0, $0.1 \mathrm{~mol} / \mathrm{L})$ are shown in Fig. 1(a). A pair of reversible peaks are observed at $E_{\mathrm{pa}}=0.200 \mathrm{~V}$ and $E_{\mathrm{pc}}=0.100 \mathrm{~V}$ versus SCE, and $\Delta E_{\mathrm{p}}=\left(E_{\mathrm{pa}}-E_{\mathrm{pc}}\right)$ was $0.100 \mathrm{~V}$. The electrode process was quasi-reversible, with $\Delta E_{\mathrm{p}}$, greater than that expected for a reversible system. Figure 1(b) shows that the anodic and cathodic peak currents $\left(I_{\mathrm{p}}\right)$ were linearly dependent on $v$ at scan rates of $10-800 \mathrm{mV} / \mathrm{s}$. A linear correlation was obtained between the peak current and the scan rate, indicating that the control of the redox process was diffusion independent (Fig. 1(b)).

An approximate estimate of the surface coverage $(\Gamma)$ of the modified $\mathrm{CPE}\left(\mathrm{mol} / \mathrm{cm}^{2}\right)$ was made by the method used by Sharp et al. [44]. According to this method, the peak current is related to the surface concentration of electroactive species by the following equation:

$$
I_{\mathrm{p}}=n^{2} F^{2} A \Gamma \nu / 4 R T
$$

where $n$ represents the number of electrons involved in the reaction, $A\left(\mathrm{~cm}^{2}\right)$ is the surface area of the PBDCNPE, $\Gamma$ $\left(\mathrm{mol} / \mathrm{cm}^{2}\right)$ is the surface coverage, and the other symbols have their usual meanings. The surface concentration of PBD calculated from the slope of the anodic peak current versus scan rate (Fig. 1(b)) is $\Gamma=8.2 \times 10^{-8} \mathrm{~mol} / \mathrm{cm}^{2}$ for $n=2$.

Laviron [45] derived general expressions for the linear potential sweep voltammetric response of surface-confined elec-
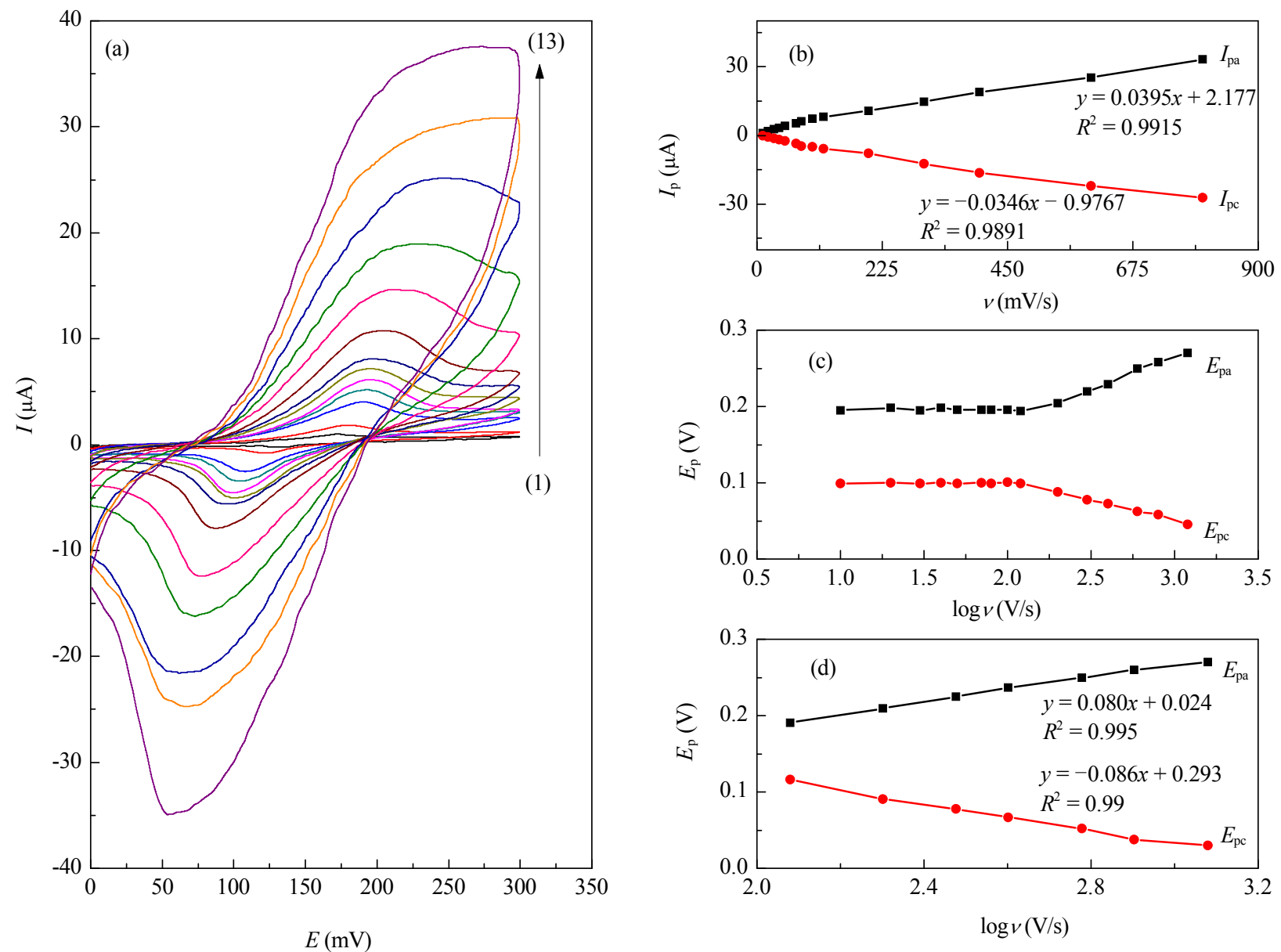

Fig. 1. (a) CVs of PBDCNPE in phosphate buffer (pH 7.0, $0.1 \mathrm{~mol} / \mathrm{L}$ ) at scan rates of 10 (1), 20 (2), 50 (3), 70 (4), 80 (5), 100 (6), 120 (7), 200 (8), 300 (9), 400 (10), 600 (11), 800 (12), and 1200 (13) mV/s; (b) Variations in $I_{\mathrm{p}}$ with scan rate; (c) Variations in $E_{\mathrm{p}}$ with logarithm of scan rate; (d) Magnification of the same plots for high scan rates. 
troactive species:

$$
\begin{gathered}
\log k_{\mathrm{s}}=\alpha \log (1-\alpha)+(1-\alpha) \log \alpha- \\
\log \left(R T / n_{\alpha} F v\right)-\alpha(1-\alpha) n_{\alpha} F \Delta E_{\mathrm{p}} / 2.3 R T
\end{gathered}
$$

A plot of $E_{\mathrm{p}}$ as a function of $\log v$ yields a straight line with a slope equal to $2.3 R T /(1-\alpha) n F$ for the anodic peak (Fig. 1(d)). The values of $\alpha$ and $k_{\mathrm{s}}$ for PBD oxidation were determined to be 0.31 and $1.17 \mathrm{~s}^{-1}$, respectively, using such a plot and Eq. (2).

\subsection{Effect of $\mathrm{pH}$ on peak potential}

The voltammetric behavior of the PBDCNPE was characterized at various $\mathrm{pH}$ values using CV. Figure 2 shows the CVs of the modified electrode in solutions at various $\mathrm{pH}$ values ranging from 3.0 to 10.0. The anodic peak potential was $\mathrm{pH}$ dependent. The inset in Fig. 2 shows $E^{\circ}$ as a function of $\mathrm{pH}$. The results show that the slope $\left(E^{\circ} / \mathrm{pH}\right)$ is $-52.2 \mathrm{mV} / \mathrm{pH}$ over the $\mathrm{pH}$ range from 2.0 to 10.0 . This slope was close to the Nernstian value of $-59.2 \mathrm{mV}$ for a two-electron, two-proton process [46]. Two protons are therefore transferred in the redox reaction in the $\mathrm{pH}$ range $3.0-10.0$.

\subsection{Electrocatalytic oxidation of DA at PBDCNPE}

Figure 3 shows the cyclic voltammetric responses from the electrochemical oxidation of $0.2 \mathrm{mmol} / \mathrm{L} \mathrm{DA}$ at the PBDCNPE (curve (5)), PBDCPE (curve (4)), and CPE (curve (2)). As shown, the anodic peak potentials for DA oxidation at the PBDCNPE and PBDCPE were about $180 \mathrm{mV}$, whereas at the unmodified CPE, the peak potential was about $450 \mathrm{mV}$. From these results, it was concluded that the best electrocatalytic effect for DA oxidation was observed at the PBDCNPE. The peak potential of DA oxidation at the PBDCNPE shifted by about 270 $\mathrm{mV}$ toward negative values compared with that at the unmodified CPE.

A comparison of DA oxidations at the PBDCPE and the PBDCNPE shows a significant enhancement of the anodic peak current at the PBDCNPE relative to that obtained at the

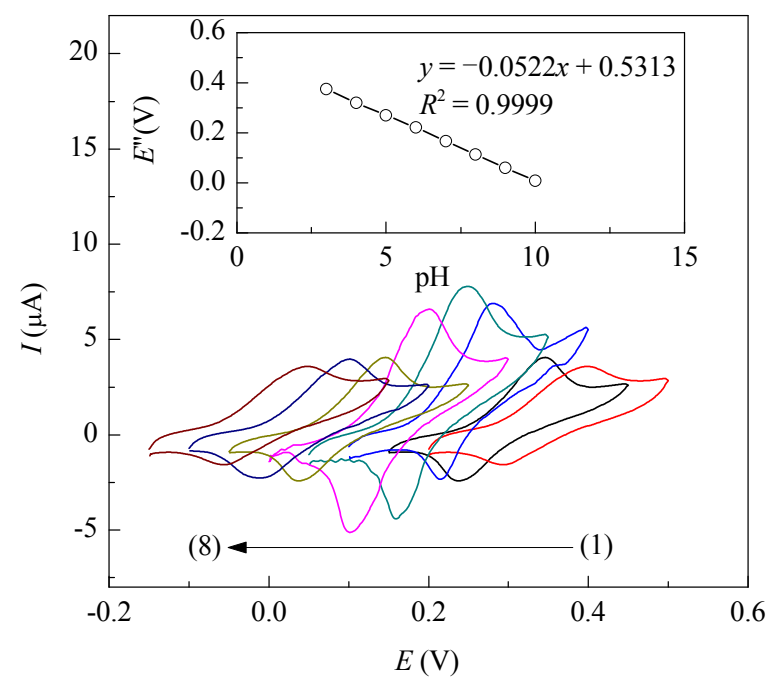

Fig. 2. CVs (at $100 \mathrm{mV} / \mathrm{s}$ ) of PBDCNPE at buffered $\mathrm{pH}$ values of $\mathrm{pH}=3$ (1), 4 (2), 5 (3), 6 (4), 7 (5), 8 (6), 9 (7), and 10 (8). Inset: Plot of $E^{\prime \prime}$ versus $\mathrm{pH}$.

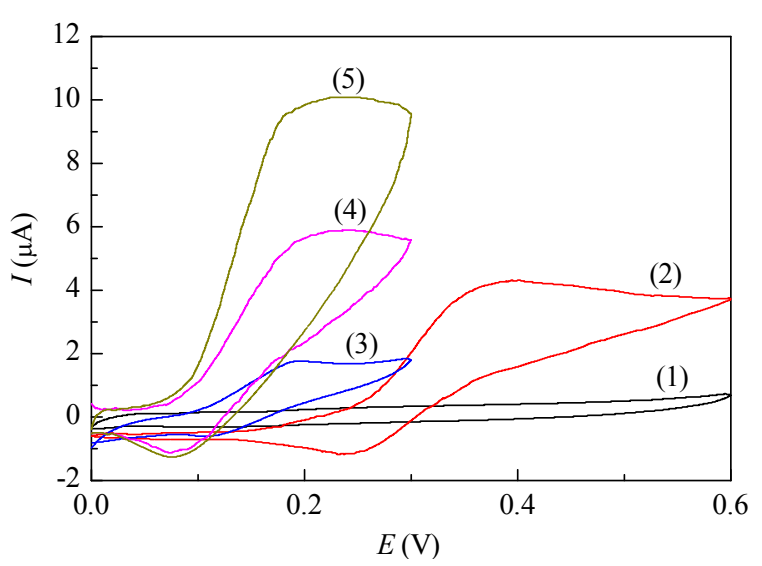

Fig. 3. CVs of (1) CPE in $0.1 \mathrm{~mol} / \mathrm{L}$ phosphate buffer solution ( $\mathrm{pH} 7.0$ ) and (2) in $0.2 \mathrm{mmol} / \mathrm{L} \mathrm{DA}$; (3) as (1) for PBDCNPE; (4) and (5) as (2) at the surfaces of PBDCPE and PBDCNPE, respectively. In all cases, the scan rate is $25 \mathrm{mV} / \mathrm{s}$.

PBDCPE. The combination of CNTs and PBD therefore definitely improved the characteristics of DA oxidation. The PBDCNPE, in phosphate buffer ( $\mathrm{pH} 7.0,0.1 \mathrm{~mol} / \mathrm{L}$ ) and without DA in solution, exhibited a well-behaved redox reaction (curve (3)); upon addition of $0.2 \mathrm{mmol} / \mathrm{L} \mathrm{DA}$, there was a significant increase in the anodic peak current (curve (5)), indicating a strong electrocatalytic effect [46]. So, it is concluded that electrocatalytic behavior occurs for DA oxidation at the PBDCNPE surface via an EC' catalytic mechanism (Scheme 1). In this mechanism, DA is oxidized in a catalytic chemical reaction ( $C^{\prime}$ ) by the oxidized form of PBD ( $\mathrm{PBD}_{\mathrm{ox}}$ ), which is produced via an electrochemical reaction (E). Therefore, when the PBD is oxidized at a potential of $180 \mathrm{mV}$, DA can also be oxidized at this potential [33].

\subsection{Effect of scan rate on oxidation of DA}

The effect of the scan rate on the electrocatalytic oxidation of $0.2 \mathrm{mmol} / \mathrm{L}$ DA at the PBDCNPE was investigated using linear sweep voltammograms (Fig. 4(a)). The oxidation peak potential shifts with increasing scan rates towards a more positive potential, confirming kinetic control of the electrochemical reaction.

A plot of peak height $\left(I_{\mathrm{p}}\right)$ against the square root of the scan rate $\left(v^{1 / 2}\right)$ in the range $5-100 \mathrm{mV} / \mathrm{s}$ was constructed (Fig. $4(\mathrm{~b})$ ); it was found to be linear, suggesting that at sufficient overpotential, the process is diffusion rather than surface controlled. A plot of the sweep-rate-normalized current $\left(I_{\mathrm{p}} / v^{1 / 2}\right)$ versus sweep rate (Fig. 4(c)) exhibits the characteristic shape of an $\mathrm{EC}^{\prime}$ cat process. Also, from the points in the rising part of the

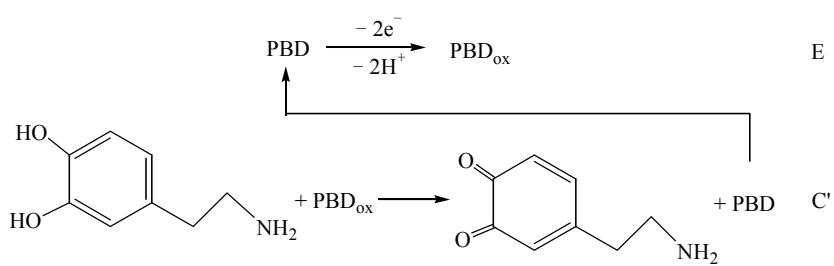

Scheme 1. Electrocatalytic reaction mechanism for DA oxidation at the PBDCNPE surface. 
voltammogram (known as the Tafel region), which is affected by the electron-transfer kinetics between $\mathrm{DA}$ and the PBDCNPE, a charge-transfer coefficient of $\alpha=0.51$ was obtained for DA oxidation.

\subsection{Chronoamperometric measurements}

Chronoamperometry was used to investigate the processes at the CMEs. Figure 5 shows chronoamperometric measure-

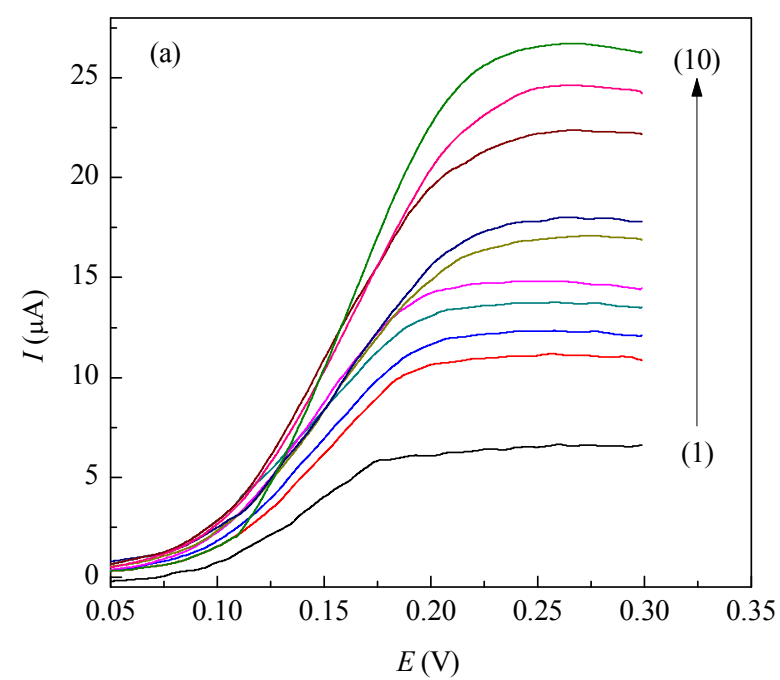

ments for DA at the PBDCNPE. It shows the current-time profiles obtained at a working electrode potential of $300 \mathrm{mV}$ for various concentrations of DA. In the chronoamperometric studies, we determined the diffusion coefficient of DA at the PBDCNPE based on the Cottrell equation [46]. Under diffusion control, a plot of $I$ versus $t^{-1 / 2}$ will be linear, and the value of $D$ can be obtained from the slope. Inset (a) in Fig. 5 shows the experimental plots with the best fits for the different DA concentrations used. The slopes of the resulting straight lines were
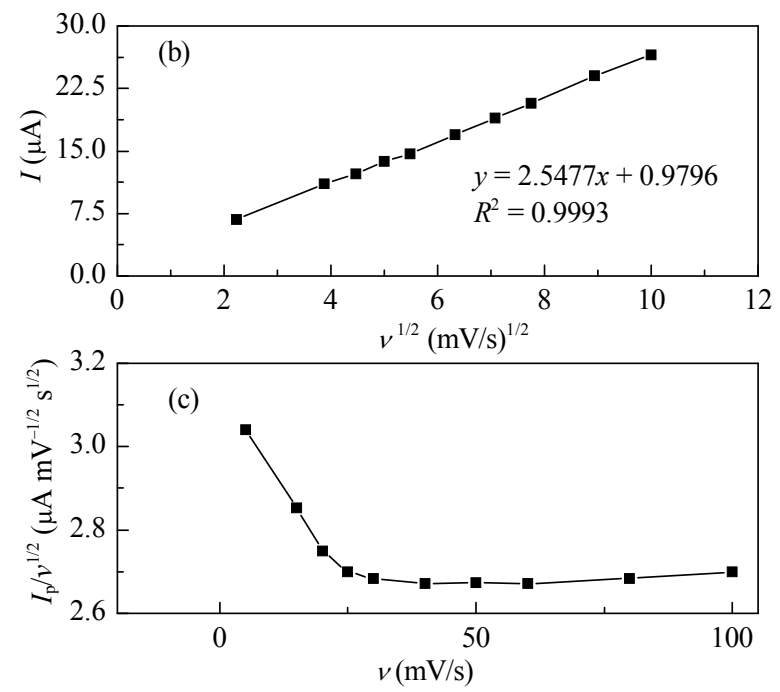

Fig. 4. (a) Linear sweep voltammograms of PBDCNPE in $0.1 \mathrm{~mol} / \mathrm{L}$ phosphate buffer (pH 7.0) containing $0.2 \mathrm{mmol} / \mathrm{L}$ DA at scan rates of 5 (1), 15 (2), 20 (3), 25 (4), 30 (5), 40 (6), 50 (7), 60 (8), 80 (9), and 100 (10) mV/s; (b) Variations in electrocatalytic current with the square root of scan rate; (c) Variations in scan-rate-normalized current $\left(I_{\mathrm{p}} / v^{1 / 2}\right)$ with scan rate.

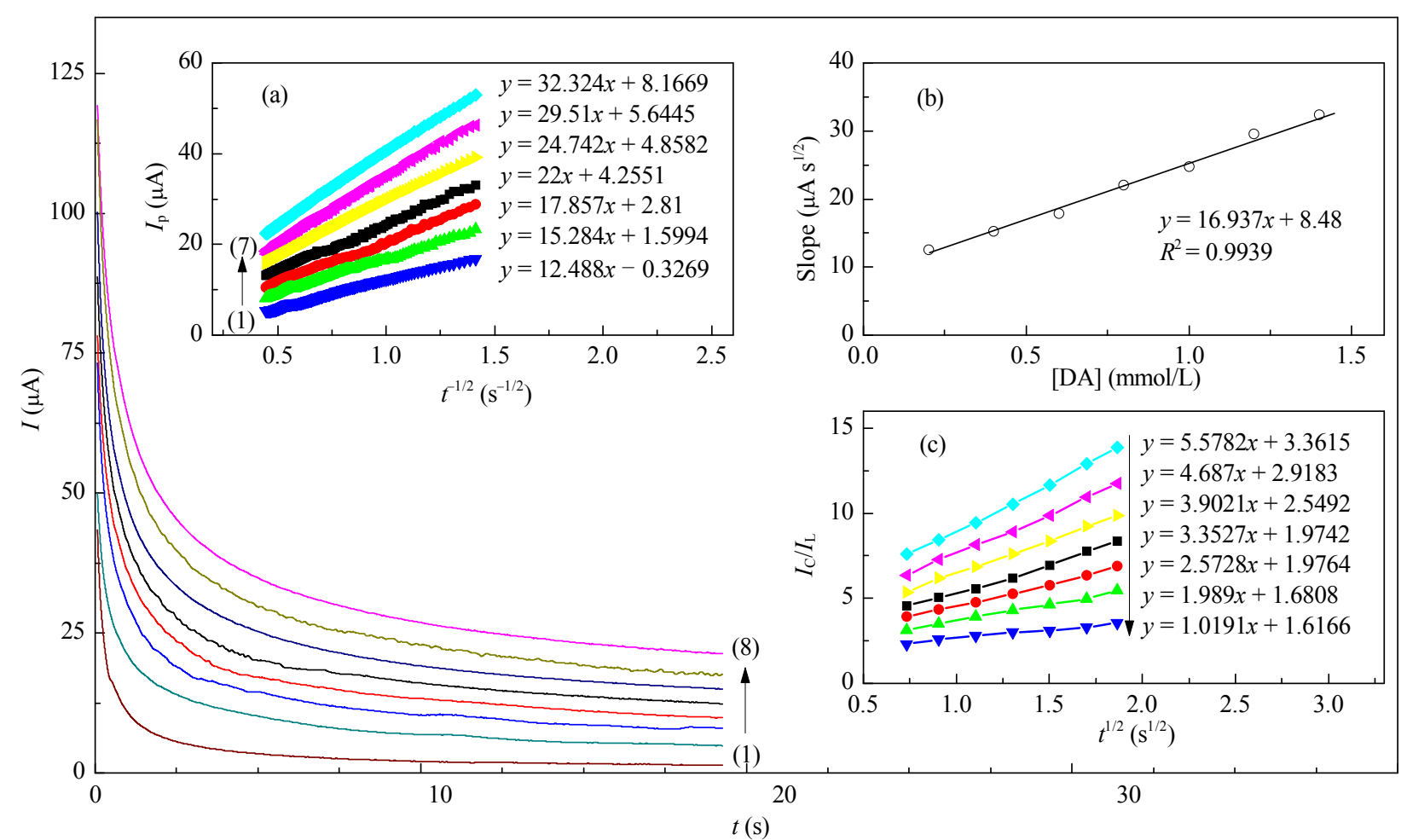

Fig. 5. Chronoamperograms obtained at PBDCNPE in phosphate buffer solution ( $\mathrm{pH} 7.0,0.1 \mathrm{~mol} / \mathrm{L}$ ) for DA concentrations of 0.0 (1), 0.2 (2), 0.4 (3), 0.6 (4), 0.8 (5), 1.0 (6), 1.2 (7), and 1.4 (8) mmol/L DA. Insets: (a) plots of $I$ versus $t^{-1 / 2}$ obtained from chronoamperograms (2)-(8), (b) plot of slopes of straight lines against DA concentration, and (c) dependence of $I_{\mathrm{C}} / I_{\mathrm{L}}$ on $t^{1 / 2}$ derived from chronoamperograms. 
plotted versus the DA concentration (Fig. 5, inset b). From the slope of this curve, the value of $D$ was found to be $1.52 \times 10^{-6}$ $\mathrm{cm}^{2} / \mathrm{s}$.

Chronoamperometry can also be used to evaluate the catalytic rate constant, $k$, for the reaction between DA and the PBDCNPE according to Galus's method [47]:

$$
I_{C} / I_{L}=\gamma^{1 / 2}\left[\pi^{1 / 2} \operatorname{erf}\left(\gamma^{1 / 2}\right)+\exp (-\gamma) / \gamma^{1 / 2}\right]
$$

where $I_{C}$ is the catalytic current of DA at the PBDCNPE, $I_{\mathrm{L}}$ is the limiting current in the absence of DP, and $\gamma=k C_{\mathrm{b}} t\left(C_{\mathrm{b}}\right.$ is the bulk concentration of DA) is the argument of the error function. In the cases where $\gamma$ exceeds 2 , the error function is almost equal to 1 , so the above equation can be reduced to:

$$
I_{\mathrm{C}} / I_{\mathrm{L}}=\pi^{1 / 2} \gamma^{1 / 2}=\pi^{1 / 2}\left(k C_{\mathrm{b}} t\right)^{1 / 2}
$$

where $t$ is the time elapsed (s). The above equation can be used to calculate the rate constant of the catalytic process $(k)$. Based on the slope of the $I_{C} / I_{L}$ versus $t^{1 / 2}$ plot, $k$ can be obtained for a given DA concentration. Such plots obtained from the chronoamperograms in Fig. 5 are shown in inset (c). From the values of the slopes, the average value of $k$ was found to be $4.36 \times 10^{3}$ $\mathrm{mol}^{-1} \mathrm{~L} \mathrm{~s}^{-1}$. The value of $k$ explains the sharp feature of the catalytic peak observed for catalytic oxidation of DA at the surface of the PBDCNPE. Finally, the heterogeneous rate constant of the catalytic reaction was calculated to be $k=3.586 \times 10^{-1} \mathrm{~cm} / \mathrm{s}$.

\subsection{Differential pulse voltammetry investigations and limit of detection}

Differential pulse voltammetry (DPV) was used to determine the concentration of DA. Figure 6 shows the DPVs obtained for the oxidation of different concentrations of DA at the PBDCNPE. The dependence of the peak current on the DA concentration is shown in the inset of Fig. 6. This inset clearly shows that the plot of peak current versus DA concentration consists of two linear segments with different slopes, corresponding to two different substrate concentration ranges. The decrease in sensitivity (slope) in the second linear range is caused by kinetic limitations. From analysis of these data, we estimated that the lower limit of detection of DA is $1.0 \mu \mathrm{mol} / \mathrm{L}$. This value is comparable to these reported by other research groups (Table 1).

\subsection{Simultaneous determination of $D A, U A$, and FA}

The main objective of this study was to detect DA, UA, and

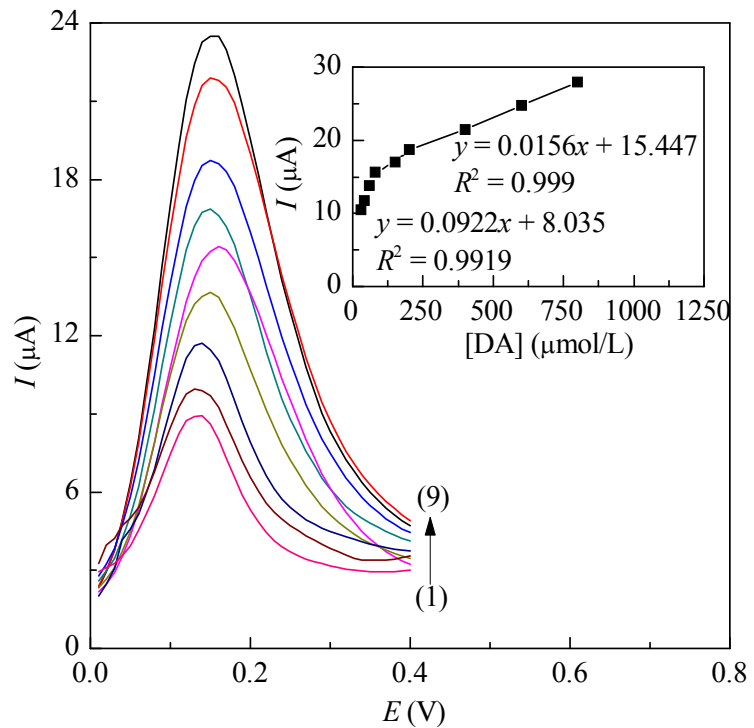

Fig. 6. DPVs of PBDCNPE in $0.1 \mathrm{~mol} / \mathrm{L}$ phosphate buffer solution ( $\mathrm{pH}$ 7.0) containing DA concentrations of 30 (1), 40 (2), 60 (3), 80 (4), 100 (5), $200(6), 400$ (7), 600 (8), and 800 (9) $\mu \mathrm{mol} / \mathrm{L}$. Inset: plots of electrocatalytic peak current as a function of DA concentration.

FA simultaneously. The use of the PBDCNPE for the simultaneous determination of DA, UA, and FA was demonstrated by simultaneously changing the concentrations of DA, UA, and FA. The DPV results, with three well-distinguished anodic peaks at potentials of 130,360 , and $700 \mathrm{mV}$, corresponding to the oxidation of DA, UA, and FA, respectively, showed that simultaneous determination of DA, UA, and FA at the PBDCNPE was possible (Fig. 7). In contrast, the bare electrode could not separate the voltammetric signals of these substances and an overlapping voltammogram was obtained for the analytes.

The sensitivity of the modified electrode toward the oxidation of DA was found to be $0.0906 \mu \mathrm{A} \mu \mathrm{mol}^{-1} \mathrm{~L}$, whereas the sensitivity toward DA in the absence of UA and FA was found to be $0.092 \mu \mathrm{A} \mu \mathrm{mol}^{-1} \mathrm{~L}$. It is interesting that the sensitivities of the modified electrode toward DA in the absence and presence of UA and FA were virtually the same; this indicates that the oxidation processes of DA, UA, and FA at the PBDCNPE were independent, therefore simultaneous or independent measurements of the three analytes are possible without any interference. If UA or FA affected the DA signal, the above-mentioned slopes would be different.

Table 1

\begin{tabular}{|c|c|c|c|c|c|c|}
\hline Electrode & Modifier & $\mathrm{pH}$ & $\begin{array}{l}\text { Scan rate } \\
(\mathrm{mV} / \mathrm{s})\end{array}$ & $\begin{array}{l}\text { Dynamic range } \\
(\mu \mathrm{mol} / \mathrm{L})\end{array}$ & $\begin{array}{l}\text { Detection limit } \\
(\mu \mathrm{mol} / \mathrm{L})\end{array}$ & Ref. \\
\hline$\overline{\mathrm{CPE}}$ & Poly (rhodamine B) & 7.0 & 5 & $6-1000$ & 3.99 & [48] \\
\hline $\mathrm{CPE}$ & poly (l-arginine) & 5.6 & 50 & $50-100$ & 0.5 & [49] \\
\hline $\mathrm{CPE}$ & Poly (naphthol green B) & 7.0 & 100 & $5-270$ & 0.25 & [50] \\
\hline GCE & MWCNT & 8.0 & 50 & $3-200$ & 0.8 & [51] \\
\hline $\mathrm{CPE}$ & $\begin{array}{l}\text { Horseradish peroxidase immobilized on } \\
\text { PEGylated polyurethane nanoparticles }\end{array}$ & 6.5 & 100 & $17-1900$ & 2.0 & [52] \\
\hline CPE & SDS micelles & 7.0 & 80 & $8-134$ & 3.7 & [53] \\
\hline $\mathrm{CPE}$ & PBD and MWCNT & 7.0 & 100 & $30-800$ & 1.0 & this work \\
\hline
\end{tabular}

Comparison of some electrochemical procedures used in DA determination. 

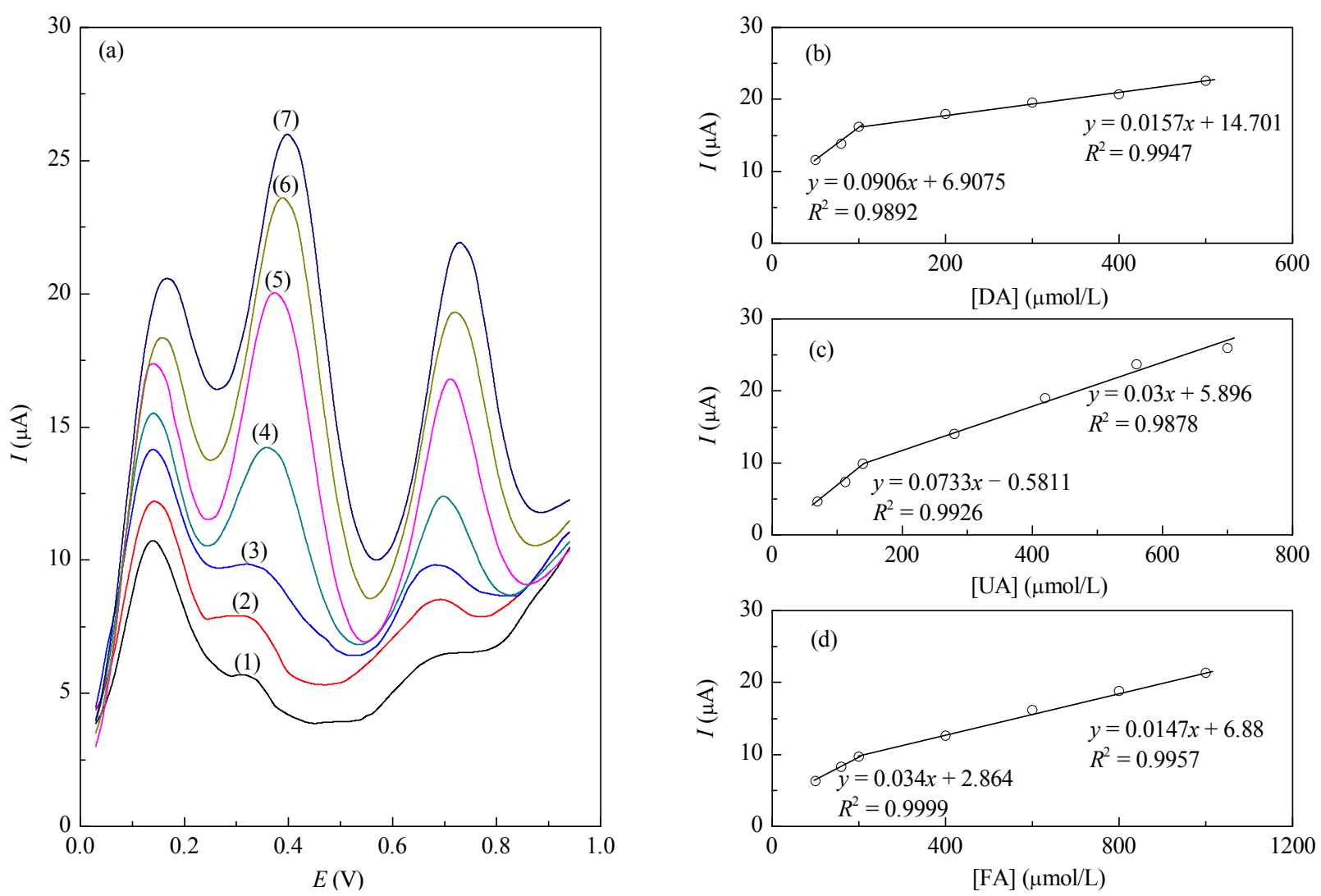

Fig. 7. (a) DPVs of PBDCNPE in $0.1 \mathrm{~mol} / \mathrm{L}$ phosphate buffer solution ( $\mathrm{pH} 7.0)$ containing different concentrations $(\mu \mathrm{mol} / \mathrm{L})$ of $\mathrm{DA}+\mathrm{UA}+\mathrm{FA}$ mixed solutions: (1) $50.0+70.0+100.0$, (2) $80.0+112.0+160.0$, (3) $100.0+140.0+200.0$, (4) $200.0+280.0+400.0$, (5) $300.0+420.0+600.0$, (6) $400.0+560.0+800.0$, and (7) $500.0+700.0+1000.0$. (b), (c), and (d) are plots of peak currents as a function of DA, UA, and FA concentration, respectively.

\section{8. $\quad$ Interference study}

The influence of various foreign species on the determination of $0.1 \mathrm{mmol} / \mathrm{L}$ DA was investigated. The tolerance limit was taken as the maximum concentration of the foreign substances, which caused an approximately $\pm 5 \%$ relative error in the determination. The tolerated concentrations of foreign substances were $1.0 \mathrm{~mol} / \mathrm{L}$ for $\mathrm{Na}^{+}, \mathrm{Cl}^{-}, \mathrm{F}^{-}, \mathrm{S}^{2-}, \mathrm{CO}_{3}{ }^{2-}, \mathrm{HCO}_{3}{ }^{-}$, $\mathrm{NO}_{3}^{-}$, and $\mathrm{K}^{+} ; 1 \mathrm{mmol} / \mathrm{L}$ for UA, FA, captopril, and $\mathrm{N}$-acetyl cysteine; and $0.1 \mathrm{mmol} / \mathrm{L}$ for ascorbic acid, isoprenaline, epinephrine, and levodopa.

\subsection{Repeatability and stability of PBDCNPE}

The ability to generate a reproducible electrode surface was examined using CV data from five separately prepared PBDCNPEs obtained at the optimum solution $\mathrm{pH}$. The calculated relative standard deviations for various parameters $(1 \%-4 \%)$ indicated that the surface reproducibility was satisfactory. This degree of reproducibility is virtually the same as that expected for an ordinary carbon paste surface [54]. In addition, the long-term stability of the PBDCNPE was tested over a 3-week period. When CVs were recorded after the modified electrode was stored in the atmosphere at room temperature, the peak potential for DA oxidation was unchanged, and the current signals showed a decrease of less than $2.3 \%$ relative to the initial response.
The antifouling properties of the modified electrode toward DA oxidation and its oxidation products were investigated by recording the $\mathrm{CVs}$ of the modified electrode before and after use in the presence of DA. CVs were recorded in the presence of DA after cycling the potential 10 times at a scan rate of 25 $\mathrm{mV} / \mathrm{s}$. The peak potentials were unchanged, and the currents decreased by less than $2.3 \%$. This showed that at the surface of the PBDCNPE, the sensitivity increases and the fouling effects of the analyte and its oxidation product also decrease.

\subsection{Real sample analysis}

To demonstrate the catalytic oxidation of DA in real samples, we used voltammetric determination of DA in a DA ampoule purchased from local sources. The determination of DA in the ampoule samples was carried out using multipoint standard addition to prevent any matrix effects. The amount of unknown DA in the ampoule was obtained by extrapolating the plot. The average amount of DA in the injection was found to be $0.97 \mathrm{mg}$, with a recovery of $97 \%$, a value in good agreement with the nominal value on the ampoule label (1.0 mg).

Also, the applicability of the PBDCNPE for simultaneous determination of DA, UA, and FA in real samples was investigated using the electrode in mixture solutions. Table 2 shows the percentage recoveries of DA, UA, and FA in synthetic solutions with the PBDCNPE using the standard addition method; the results are good for DA, UA, and FA. 
Table 2

Recoveries of DA, UA, and FA in synthetic solutions with PBDCNPE using standard addition method.

\begin{tabular}{|c|c|c|c|c|c|c|c|c|}
\hline \multicolumn{3}{|c|}{$\begin{array}{c}\text { Synthetic solutions } \\
(\mu \mathrm{mol} / \mathrm{L}) \\
\end{array}$} & \multicolumn{3}{|c|}{$\begin{array}{c}\text { Found } \\
(\mu \mathrm{mol} / \mathrm{L})\end{array}$} & \multicolumn{3}{|c|}{$\begin{array}{c}\text { Recovery } \\
(\%)\end{array}$} \\
\hline DA & UA & FA & DA & UA & FA & DA & UA & FA \\
\hline 200 & - & - & 202.2 & - & - & 101.1 & - & - \\
\hline 100 & - & - & 98.7 & - & - & 98.70 & - & - \\
\hline 200 & - & 400 & 198.9 & - & 401.8 & 99.45 & - & 100.45 \\
\hline 200 & 400 & - & 201.1 & 398.6 & - & 100.55 & 99.65 & - \\
\hline 200 & 400 & 400 & 203.1 & 397.5 & 399 & 101.55 & 99.37 & 99.75 \\
\hline 150 & 300 & 300 & 148.7 & 302.5 & 298.5 & 99.13 & 100.83 & 99.50 \\
\hline 100 & 200 & 200 & 102.5 & 201.5 & 198.5 & 102.5 & 100.75 & 99.25 \\
\hline
\end{tabular}

\section{Conclusions}

A CPE modified with PBD and CNTs was fabricated and used for electrocatalytic determination of DA. The electro-oxidation of DA at the surface of the PBDCNPE occurred at a potential about $270 \mathrm{mV}$ less positive than that for the bare CPE. The use of the PBDCNPE for the simultaneous determination of DA, UA, and FA was demonstrated. The detected potential differences of 230, 570, and $340 \mathrm{mV}$ between DA-UA, DA-FA, and UA-FA, respectively, were large enough to determine DA, UA, and FA individually and simultaneously. Finally, this electrode was used for the determination of DA in a DA injection using the standard addition method. The high current sensitivity, low detection limit, and high selectivity of the PBDCNPE for the detection of DA proved its potential as a sensor.

\section{Acknowledgements}

The authors wish to thank the Yazd University Research Council, the IUT Research Council and Excellence in Sensors for financial support of this research.

\section{References}

[1] Cooper J R, Bloom F E, Roth R H. The Biochemical Basis of Neuropharmacology. New York: Oxford University Press, 1982

[2] Michael D J, Wightman R M. J Pharm Biomed Anal, 1999, 19: 33
[3] Wightman R M, May L J, Michael A C. Anal Chem, 1988, 60: 769

[4] Hows M E P, Lacroix L, Heidbreder C, Organ A J, Shah A J.J Neurosci Meth, 2004, 138: 123

[5] Sabbioni C, Saracino M A, Mandrioli R, Pinzauti S, Furlanetto S, Gerra G, Raggi M A. J Chromatogr A, 2004, 1032: 65

[6] Kumarathasan P, Vincent R. J Chromatogr A, 2003, 987: 349

[7] Tsunoda M, Aoyama C, Nomura H, Toyoda T, Matsuki N, Funatsu T. J Pharm Biomed Anal, 2010, 51: 712

[8] Peterson Z D, Collins D C, Bowerbank C R, Lee M L, Graves S W.J Chromatogr B, 2002, 776: 221

[9] Lane R F, Blaha C D. Langmuir, 1990, 6: 56

[10] Mazloum-Ardakani M, Beitollahi H, Ganjipour B, Naeimi H, Nejati M. Bioelectrochemistry, 2009, 75: 1

[11] Manjunatha J G, Kumara Swamy B E, Mamatha G P, Chandra U, Niranjana E, Sherigara B S. Int J Electrochem Sci, 2009, 4: 187

[12] Mazloum-Ardakani M, Sheikh-Mohseni M A, Beitollahi H, Benvidi A, Naeimi H. TurkJ Chem, 2011, 35: 573

[13] Haper H A. Review of Physiological Chemistry. 16th Ed. San Francisco: Lange Medical Publications, 1977

[14] Wyngaarden J B, Kelley W N. Gout and Hyperuricemia. New York: Grune and Stratton, 1976

[15] Cunningham S K, Keaveny T V. Clin Chim Acta, 1978, 86: 217

[16] Mazloum-Ardakani M, Sheikh-Mohseni M A, Benvidi A. Electroanalysis, 2011, 23: 2822

[17] Hoegger D, Morier P, Vollet C, Heini D, Reymond F, Rossier J S. Anal Bioanal Chem, 2007, 387: 267

[18] Gujska E, Kuncewicz A. Eur Food Res Technol, 2005, 221: 208

[19] Holcomb I J, Fusari S A. Anal Chem, 1981, 53: 607

[20] Gregory J F III, Day B P F, Ristow K A. J Food Sci, 1982, 47: 1568

[21] Al-warthan A A. Anal Sci, 1994, 10: 919

[22] Jung M, Kim B, Boo D W, So H Y. Bull Korean Chem Soc, 2007, 28: 745

[23] Ganguly S K, Bhattachary H. Ind J Pharm Sci, 1957, 19: 170

[24] Mazloum-Ardakani M, Beitollahi H, Sheikh-Mohseni M A, Naeimi H, Taghavinia N. Appl Catal A, 2010, 378: 195

[25] Adams R N. Anal Chem, 1958, 30: 1576

[26] Mazloum-Ardakani M, Sheikh-Mohseni M A, Abdollahi-Alibeik M, Benvidi A. Analyst, 2012, 137: 1950

[27] Gholamian F, Sheikh-Mohseni M A, Naeimi H. Mater Sci Eng C, 2012, 32: 2344

[28] Mazloum-Ardakani M, Sheikh-Mohseni M A, Abdollahi-Alibeik M, Benvidi A. Sens Actuators B, 2012, 171-172: 380

[29] Habibi B, Abazari M, Pournaghi-Azar M H. Chin J Catal (催化学报), 2012, 33: 1783

\section{Graphical Abstract}

Chin. J. Catal., 2014, 35: 201-209 doi: 10.1016/S1872-2067(12)60734-7

\section{Electrocatalysis of dopamine in the presence of uric acid and folic} acid on modified carbon nanotube paste electrode

Mohammad Mazloum-Ardakani*, Mahboobe Abolhasani, Bibi-Fatemeh Mirjalili, Mohammad Ali Sheikh-Mohseni, Afsaneh Dehghani-Firouzabadi, Alireza Khoshroo

Yazd University, Iran;

Urmia University, Iran

Dopamine is oxidized in a catalytic chemical reaction by the oxidized form of a modifier $\left(\mathrm{PBD}_{\mathrm{ox}}\right)$, produced via an electrochemical reaction at a multiwalled-carbon-nanotube-modified carbon paste electrode (MWCNT in CPE).

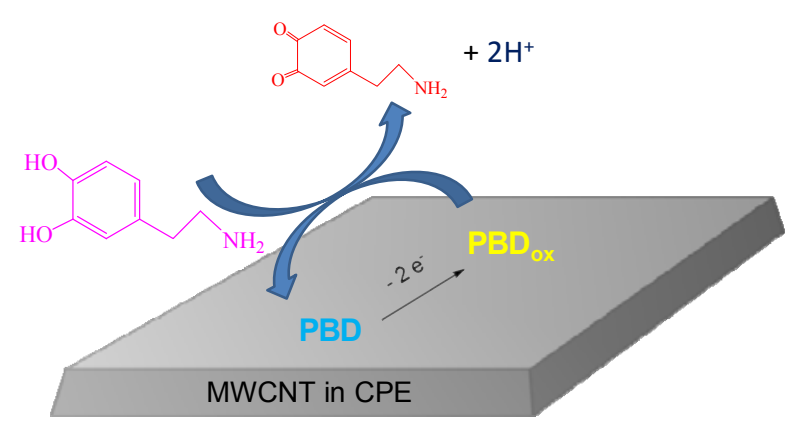


[30] Mazloum-Ardakani M, Sheikh-Mohseni M A, Mirjalili B F. Electroanalysis, 2013, 2: 2021

[31] Goyal R N, Bishnoi S. Electrochim Acta, 2011, 56: 2717

[32] Zhang X, Duan S, Xu X M, Xu S, Zhou C L. Electrochim Acta, 2011, 56: 1981

[33] Mazloum-Ardakani M, Sheikh-Mohseni M A, Mirjalili B F, Zamani L.J Electroanal Chem, 2012, 686: 12

[34] Han Y J, Stucky G D, Butler A. J Am Chem Soc, 1999, 121: 9897

[35] Jacinto M J, Kiyohara P K, Masunaga S H, Jardim R F, Rossi L M. Appl Catal A, 2008, 338: 52

[36] Xu Y M, Ning A R, Zhao J. J Colloids Interface Sci, 2001, 235: 66

[37] Ramanathan K, Bangar M A, Yun M, Chen W, Myung N V, Mulchandani A. J Am Chem Soc, 2005, 127: 496

[38] Liu H S, Song C J, Zhang L, Zhang J J, Wang H J, Wilkinson D P. J Power Sources, 2006, 155: 95

[39] Iijima S, Ichihashi T. Nature, 1993, 363: 603

[40] Mazloum-Ardakani M, Sheikh-Mohseni M A. In: Naraghi M Ed. Carbon Nanotubes - Growth and Applications. Croatia: InTech, 2011. 395

[41] Crespilho F N , Zucolotto V, Brett C M A, Oliveira O N, Nart F C. J Phys Chem B, 2006, 110: 17478

[42] Bedioui F, Villeneuve N. Electroanalysis, 2003, 15: 5

[43] Mazloum-Ardakani M, Sheikh-Mohseni M A, Abdollahi-Alibeik M. J
Mol Liq, 2013, 178: 63

[44] Sharp M, Petersson M, Edstrom K. J Electroanal Chem Interf Electrochem, 1979, 95: 123

[45] Laviron E. J Electroanal Chem Interf Electrochem, 1979, 101: 19

[46] Bard A J, Faulkner L R. Electrochemical Methods Fundamentals and Applications. New York: Wiely, 2001

[47] Galus Z. Fundamentals of Electrochemical Analysis. New York: Ellis Horwood, 1976

[48] Thomas T, Mascarenhas R, Kumara Swamy B E. J Mol Liq, 2012, 174: 70

[49] Chandrashekar B N, Kumara Swamy B E, Pandurangachar M, Sathisha T V, Sherigara B S. Colloids Surf B, 2011, 88: 413

[50] Chitravathi S, Kumara Swamy B E, Mamatha G P, Sherigara B S. J Electroanal Chem, 2012, 667: 66

[51] Alothman Z A, Bukhari N, Wabaidur S M, Haider S. Sens Actuators $B, 2010,146: 314$

[52] Fritzen-Garcia M B, Monteiro F F, Cristofolini T, Acuña J J S, Zanetti-Ramos B G, Oliveira I R W Z, Soldi V, Pasa A A, Creczynski-Pasa T B. Sens Actuators B, 2013, 182: 264

[53] Colín-Orozco E, Ramírez-Silva M T, Corona-Avendaño S, RomeroRomo M, Palomar-Pardavé M. Electrochim Acta, 2012, 85: 307

[54] Geno P W, Ravichandran K, Baldwin R P. J Electroanal Chem Interf Electrochem, 1985, 183: 155 